\title{
SOUNDPROOFING OF AIRPLANE CABINS
}

\author{
V. L. Chrisler and W. F. Snyder
}

\section{ABSTRACT}

The present article contains a report of the work done in determining the structure which will give the maximum amount of sound insulation in an airplane cabin for a minimum weight.

Various small structures were tested at frequencies varying from 150 to 1,120 cycles per second to determine the best structure available within the allowable limit of weight.

A test flight was made in a treated cabin to determine how satisfactory the structure was under operating conditions. It was found that the noise in the cabin was about the same as in a railway coach in motion.

C ONTENTS Page

I. Introduction....... 897

II. Method of measurement.

III. Method of expressing results (sensation units)

IV. Discussion of results._.

V. Tests in airplanes in flight.

VI. Description of panels.

VII. Conclusions_-_.

\section{INTRODUCTION}

This paper is the first report of an investigation which is being carried out by the Bureau of Standards for the Aeronautics Branch of the Department of Commerce for the purpose of developing, if possible, practicable methods for reducing noise in the cabins of airplanes. It is, of course, desirable to reduce the noise as much as possible at its source, and more efficient exhaust mufflers may be developed which will contribute to this end. It may also be possible to reduce somewhat the noise of the propeller. At present, however, the soundproofing of the cabin seems to afford the most promising line of attack.

This problem is not a simple one. The noise of an airplane in flight has been found ${ }^{1}$ to be of a very complex character, containing sounds of both high and low frequency. Other work on sound transmission shows that many materials are much better sound insulators at high frequencies than at low ones. The noise of an airplane engine

1 The Problem of Noise in Civil Aircraft and the Possibilities of its Elimination, W. S. Tucker, A. M. I. E. E.; January, 1928. 
is to a large extent composed of sounds of low frequency, in the region of 200 cycles per second. Tucker calls attention to the fact that in multimotored planes low-pitched beat notes may be produced when two engines are running at slightly different speeds.

In addition to the difficulty of insulating against noises of such a character the question of weight must be considered. In this respect the limitations are severe. It is also to be recognized that the engine and cabin are both attached to the same frame. This allows vibrations from the engine to be transmitted by solid conduction directly in to the cabin.

Taking all these facts into consideration, it seems that the most practicable way to obtain a reasonable degree of quiet without excessive weight is to build the cabin walls in layers. Such a structure when composed of light materials may give rise to a considerable amount of back reflection at each surface of discontinuity, thus producing on the whole a greater opacity to sound than would a homogeneous wall of the same weight.

For the determination of the best materials to be used in such a construction a large number of transmission tests were made on common materials, heavy and light-the lightest being a sheet of wrapping paper. In these experiments the transmission was measured at three different frequency bands, $150-220,400-470$, and 1,000-1,120 cycles per second. It was felt that the lowest band would represent fairly well the fundamental frequencies that characterize the noise from the engine exhaust, while the highest band would correspond approximately to overtones or other high-pitched noises that may occur with any considerable intensity.

\section{METHOD OF MEASUREMENT}

The method used in measuring the sound transmission of the various materials and their combinations was that described in a previous publication. ${ }^{2}$ In all these measurements the test panels were placed in the horizontal opening between the upper and lower rooms in the sound chamber building. It was found advisable to reduce this opening to fit the size of the sheets of material tested as cross supports were thus avoided. This reduction was effected by the use of 8-inch concrete blocks. The size of the opening used was $21 \frac{1}{2}$ by 40 inches. The samples were placed on top of this opening and sealed around the edges to prevent sound leakage.

All the materials tested had relatively high values of sound transmission, in comparison with which any transmission through the concrete blocks was negligible.

2 B. S. Sci. Paper No. 526, Transmission and Absorption of Sound by Some Building Materials. 


\section{METHOD OF EXPRESSING RESULTS (SENSATION UNITS)}

All results given in this paper and in the previous publication above referred to ${ }^{3}$ have been obtained by use of the telephone receiver as a detector and measurer of sound energy. The indications of this instrument are given on what is called the physical scale, which measures the energy of the sound wave. But the instrument most universally used for detecting sound and estimating its intensity is the human ear, and unfortunately the ear does not respond according

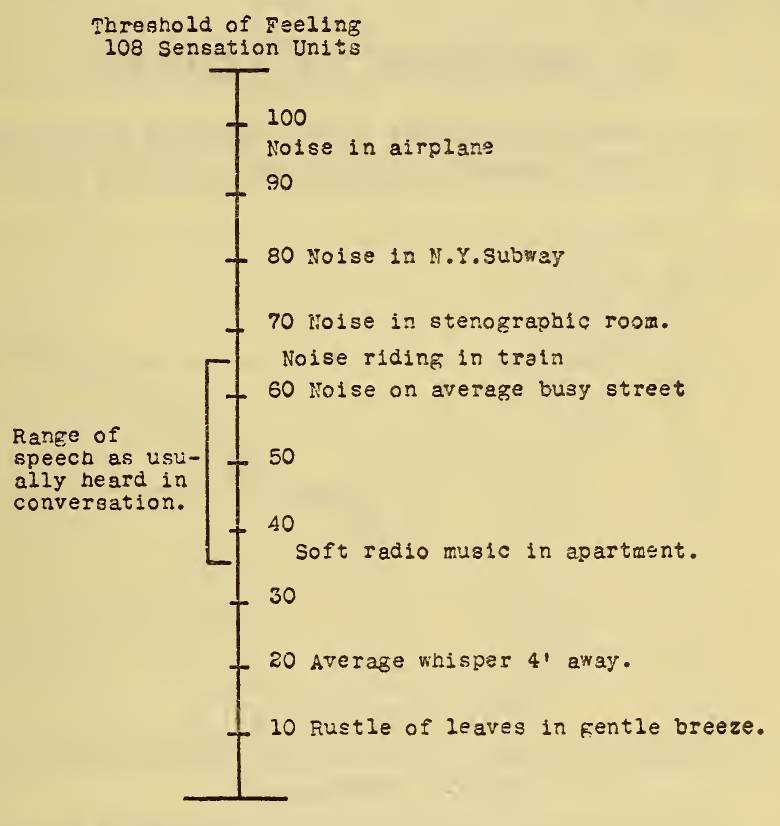

Threshold of Audibility.

Figure 1.-Ear sensation scale

to the physical scale. As the intensity of a sound increases steadily on the physical scale the response of the ear fails to keep pace with it. There appears to be in the ear a regulating or protective mechanism whose nature is not clearly understood, which, like the wellknown mechanism of the eye, protects that organ against excessive stimulation. Experience shows that the response of the ear is proportional to the logarithm of the physical intensity; that is, energies proportional to 10,100 , and 1,000 would produce in the ear effects proportional to 1,2 , and 3 , respectively. This logarithmic scale has been termed the ear scale.

A slight modification of this scale has been employed for some time by telephone engineers, ${ }^{4}$ and is used on all audiometers made

- Fletcher, Bell Telephonə Laboratories, Reprint B-152-1, J. Frank. Inst.; September, 1923. 
by the Western Electric Co. This scale merely multiplies the numbers of the ear scale by 10 , the unit of this new scale being that fractional change in intensity which is approximately the smallest that the average ear can detect. For this reason it is called a sensation unit. In the example given above, intensities corresponding to 1,2 , and 3 on the ear scale would be represented by 10,20 , and 30 sensation units.

Wallace Waterfall ${ }^{5}$ has suggested a way of illustrating the values of sensation units in familiar terms. We may call it an ear sensation scale. (Fig. 1.)

\section{DISCUSSION OF RESULTS}

When the work was first started, it was thought that possibly some materials, such as fiber boards, might have a greater degree of sound

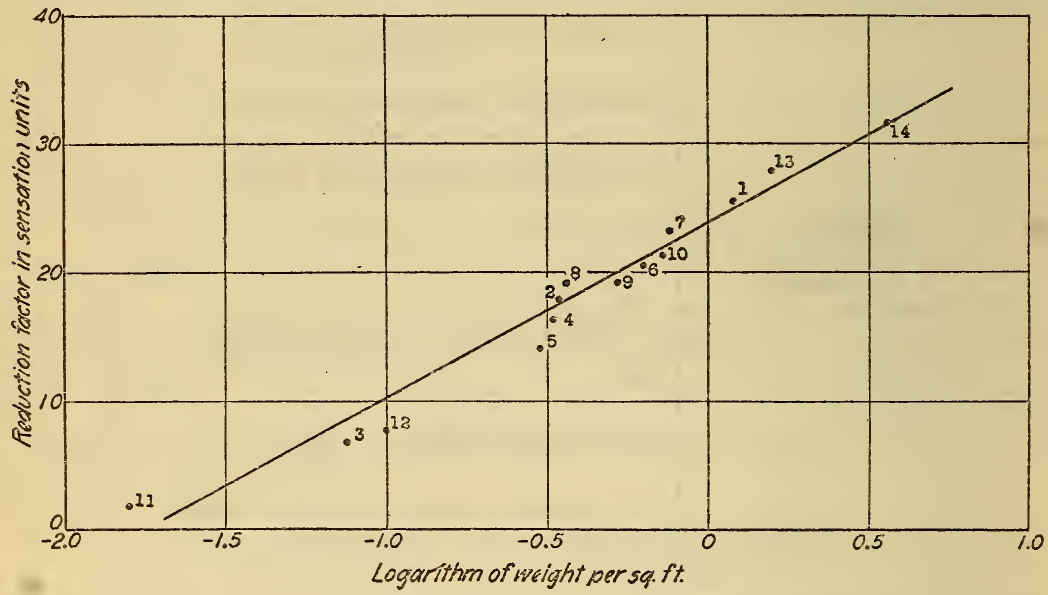

Figure. 2.-Relation between reduction factor and logarithm of panel weight (single sheets)

insulation than a sheet of metal of the same weight. When the results were plotted-the reduction factors in sensation units against the logarithm of the weight per square foot-a straight line was obtained (fig. 2), the points in every case following close enough to the line to be within experimental error. This indicated that weight was the predominating factor rather than the nature of the material.

The next attempt was to use two sheets of material with an air space between them. Two sheets of aluminum with a $13 / 4$-inch air space between them gave an average reduction factor of 14.6 sensation units, while a single sheet of the same aluminum gave 17.9. When this result was first obtained it was thought to be due to some error in measurement, but a repetition gave the same result. Sheets

$\checkmark$ Engineering News Record, p. 60; Jan. 10, 1929. 
of fiber board and of glass were tested in the same way. With these materials the presence of an air space showed a slight decrease in transmission compared with that of a single sheet, but, at least at low frequencies, the advantage gained was not enough to compensate for the increased weight.

It appears that two thin sheets of metal may be so flexible that the air between them may act as a mechanical tie, causing the two sheets to vibrate together and thus transmit sound. With more rigid materials, such as glass, this effect is less noticeable and a slight improvement in opacity may result. The point for this combination (panel 20) falls just a little above the straight line which was drawn for homogeneous materials (fig. 3 ). Had the air

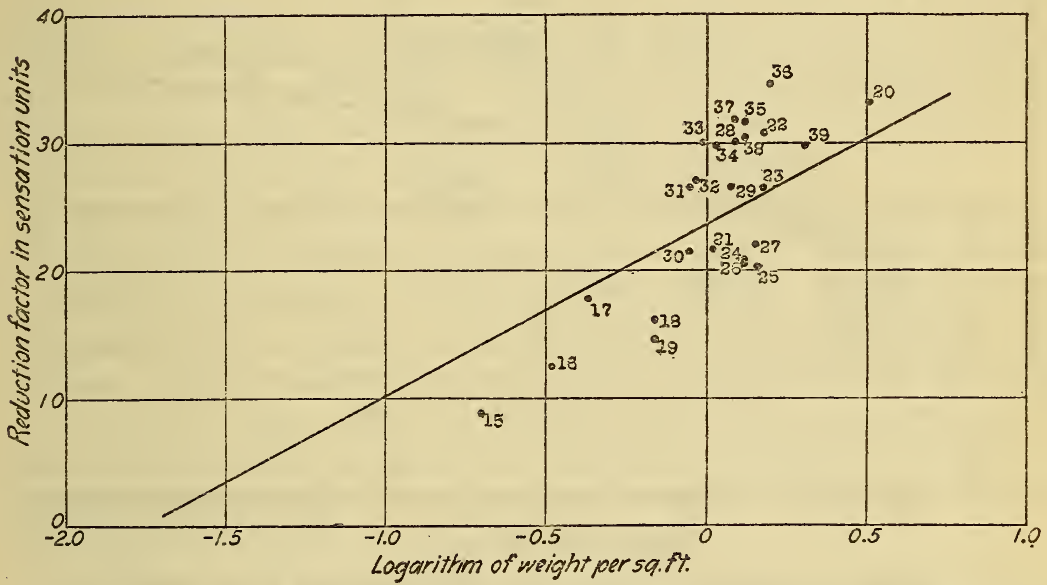

FrGURE 3.-Relation between reduction factor and logarithm of panel weight (composite structures)

space been very effective the point would have been found much higher. For two sheets of one-half inch Insulite (panel 22) there is quite an improvement, the point coming considerably above the line.

Insulite is not as stiff as glass, and, therefore, by the previous reasoning should not have given a lower transmission. Insulite, however, possesses a quality not found in glass or metal, which may account for this difference. This is its greater absorptive power for sound, which may be from 15 to 20 per cent as compared with from 1 to 3 per cent for glass and metal. In the case of fiber-board sheets separated by an air space the absorption occurring at each back reflection prevents the sound from building up in the air space to an intensity sufficient to penetrate the second sheet to the same extent as with less absorbent materials.

If this is correct, the introduction of absorbing material between two sheets of thin metal, such as aluminum, should decrease the 
transmission of the combination. Panel 36 was thus constructed and, as may be seen in Figure 3, its reduction factor came out about eight sensation units greater than might have been expected on the basis of weight alone. In building construction it has been found ${ }^{6}$ that no appreciable improvement is obtained by introducing sound-absorbing materials between two masonry walls or between two solid plaster partitions separated by a small distance. It is remarkable that this same rule does not seem to apply to very light structures.

There is considerable freedom of choice in the filling material. Balsam wool, cotton, and hair felt were tried with similar results.

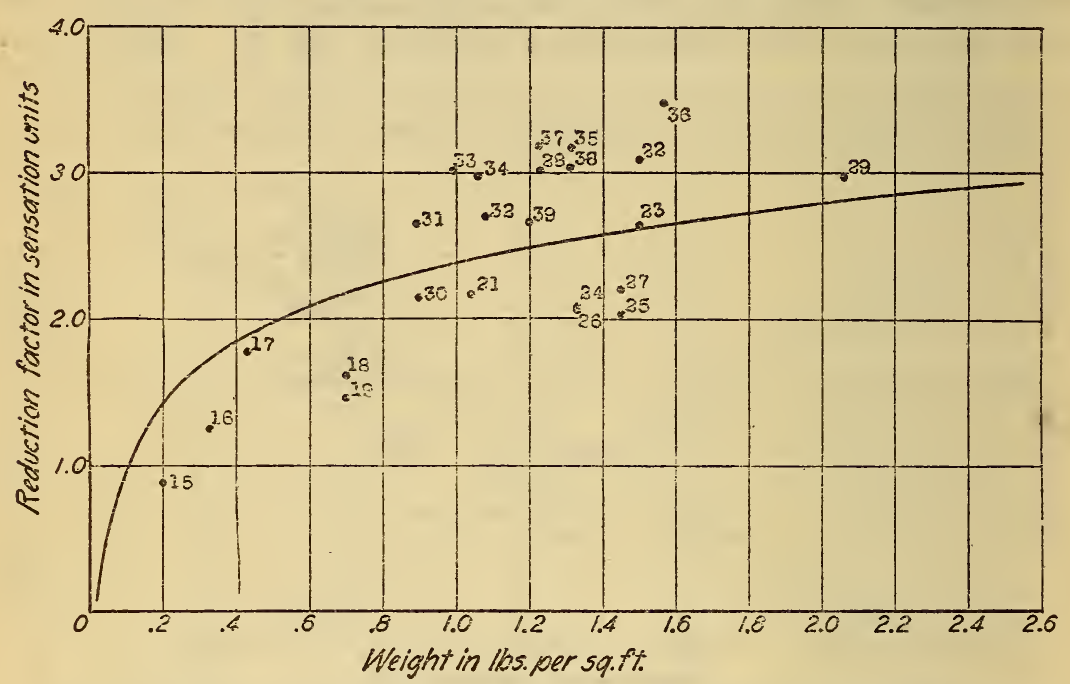

FIGURE 4.-Relation between reduction factor and panel weight

Such an arrangement gives a reduction factor which is as great as might be expected from a homogeneous material of twice the weight.

Panel 38 was built with two layers of balsam wool separated by a very thin sheet of aluminum with the idea of obtaining still better results. Measurement, however, showed no improvement over panel 28, which did not contain the central sheet of aluminum. The same plan was tried in panel 39, which contained alternate layers of cotton and wrapping paper, but without satisfactory results.

A combination of sheet aluminum, absorbent material, and fiber board (panel 33) was found to give a reduction factor equivalent to that of a homogeneous partition of about three times its weight.

Figure 3 shows graphically the results obtained by various combinations of materials. The straight line, representing the values that might have been expected if the weight were the only factor to be considered, furnishes a basis of comparison. This figure gives, in general, a somewhat distorted representation, being plotted to the

${ }^{6}$ B. S. Sci. Paper No. 552; Paul Sabine, The Armour Engineer; May, 1926. 
logarithm of the weight in order to obtain the straight line. In Figure 4 the same data have been replotted, using the weight per square foot as the abscissa. From Figure 3 it might be inferred that panel 36 is the best combination, but Figure 4 shows that this panel is nearly twice as heavy as panel 33 , while its reduction factor is only five sensation units greater. Considering weight, panel 33 gives the best results of all combinations tested.

To test this further, a larger panel, No. 40, of the same structure as panel 33, was built on a light wooden frame. On test its reduction factor was found to be 36 , as compared with 30 for the smaller panel.

\section{TESTS IN AIRPLANES IN FLIGHT}

The preliminary tests above described having indicated the possibility of constructing a panel sufficiently light to be used in an airplane and yet of considerable opacity to sound, arrangements for tests in actual flight were made by the courtesy of the Army Air Corps and of the Bureau of Aeronautics of the Nary.

In these fiights a Western Electric audiometer, type 2-A, was used as a measuring instrument for intensity of sound. This instrument has certain limitations. The most intense airplane noises are of low pitch and rather too loud to be matched by the audiometer. In addition, the audiometer gives only notes of one frequency at a time, not a complex noise. But by making use of the masking effect of noises it was possbile to get a fair idea of the reduction factor of the different cabins tested. The agreement of several different observers on this point was good.

Tests were made in the cabin of a Fokker trimotored plane placed at our disposal by the Army Air Corps. The cabin of this plane was a framework covered on the outside with airplane fabric and on the inside with plywood. The reduction factor was about 10 sensation units.

A Ford trimotored plane, furnished by the Navy, had a cabin covered on the outside with corrugated duralumin. A thin layer of kapok in burlap covers was attached to the inside of this metal sheet. Over this kapok was a layer of some composition resembling leather in appearance. The windows were of plate glass approximately one-eighth inch thick. The reduction factor for this cabin was about 20 sensation units.

From audiometer measurements the average close-up intensity. of the noise of an airplane in flight is about 95 sensation units. If a cabin could be built with a reduction factor of 35 units, the intensity of the noise within the cabin ( 60 units) would be about that in a railway coach in motion. Panel 40 , of reduction factor 36 , gave promise of furnishing this result. 
Before modifying an airplane cabin in this way three model cabins were built for laboratory test, each about the actual size of the cabin of a 4-passenger Fairchild plane.

Cabin No. 1 was covered with a thickness of airplane fabric, doped and varnished as in ordinary practice. Cabin No. 2 was covered both outside and inside with 3 -ply plywood, leaving an air space of $13 / 4$ inches between the two layers. Cabin No. 3 (fig. 5) was covered on the outside with 0.02-inch duralumin, and on the inside with onefourth inch Insulite. The space between was filled with a fibrous material known as Dry Zero blanket. This is a natural fiber which is stated to have the unusual property of having the end of each tubular fiber closed.

An additional layer of 2 -inch Dry Zero blanket was placed over the Insulite, and the inside was finished by a protective coating of perforated sheet aluminum. The object of this is not materially to decrease the transmission, but to absorb such sound as may be transmitted into the cabin. It can be shown theoretically ${ }^{7}$ that if there is no absorption in a closed space the intensity in this space after a steady state is reached is the same as the intensity outside the inclosure, no matter how good a sound insulator the walls may be.

For this reason it is advisable to line the interior of the cabin with some very absorbent material to prevent the sound that does pass through from building up to a disagreeable intensity. Any material which has a relatively high absorption at the lower frequencies will serve this purpose. Unfortunately, few materials are good absorbers at low frequencies. Taking weight into consideration, Dry Zero blanket was the best absorber that was found. It has, therefore, been used in all of these tests.

The weight, in pounds per square foot of each construction (exclusive of the wooden frame), was approximately as follows:

\section{Pounds}

Cabin No.

0.1

Cabin No. 2

1. 04

Cabin No. 3

1. 24

The cabins were then placed in the reverberation room where a comparatively loud sound of varying frequency could be produced. Audiometer tests were made at four different frequency bands. The results, expressed in sensation units, are given in Table 1.

TABLE 1.-Reduction factor in sensation units for frequencies (cycles per second)

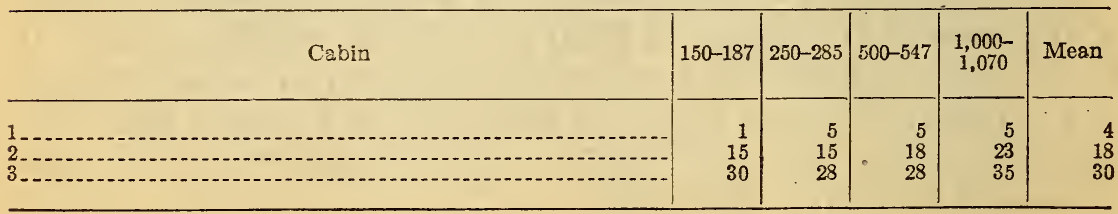

7 See footnote 2, p. 898. 
B. S. Journal of Research, RP63

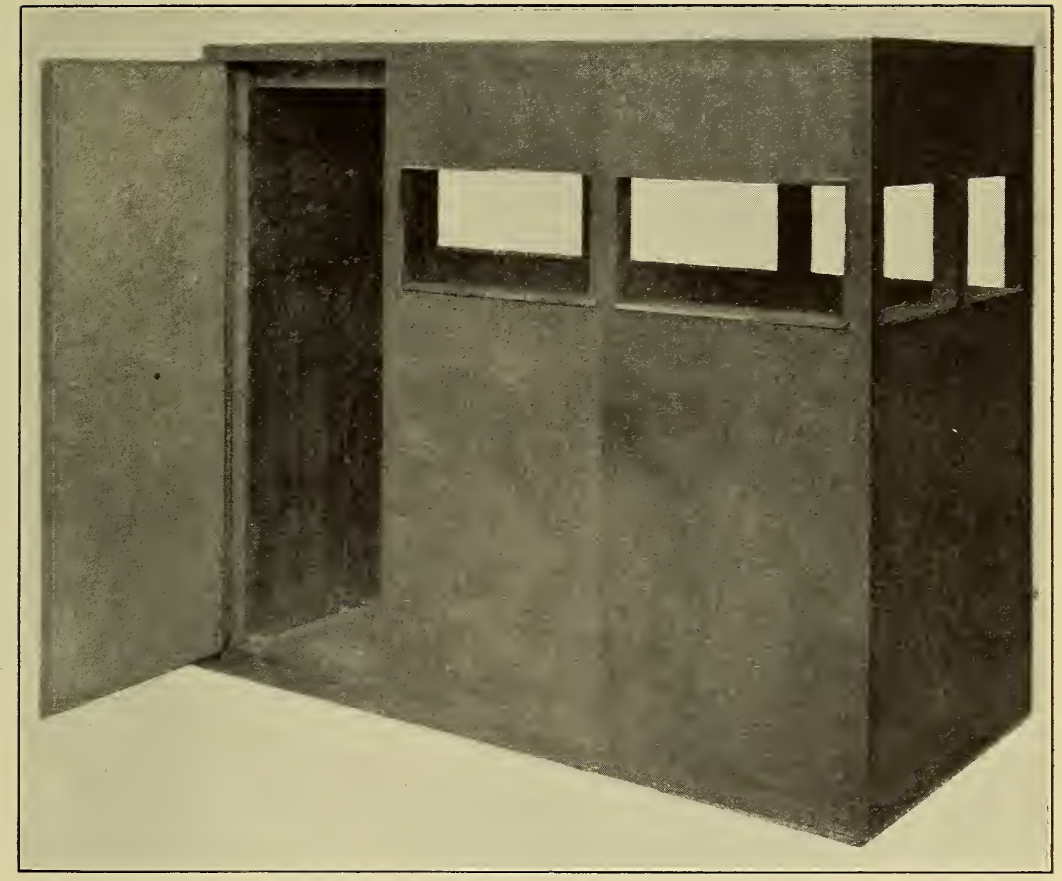

FIgure 5.-Experimental test cabin No. 3 
The results obtained with cabin No. 3 were regarded as sufficiently encouraging to warrant the modifying of an actual airplane cabin for experimental test. Permission was obtained from the Navy Department to make a temporary installation in the cabin of the Ford plane, in which one of the previous flight tests were made.

For purposes of comparison it was decided to divide the cabin into two parts, modifying one half and leaving the other in its original state.

The interior finish of the forward part of the cabin was removed, and a 2-inch layer of Dry Zero blanket placed next to the outer metal covering. Over this was fastened a layer of fiber board one fourth inch thick. Over the fiber board was placed another 2-inch layer of Dry Zero blanket, and the inside was finished with perforated sheet aluminum. The windows, being of rather thin glass, would have interfered with the tests, and were also covered. To give results equivalent to the rest of the structure the glass should have been one-fourth inch thick.

The measurements in flight were made by three observers. The average reduction factor of the treated portion of the cabin was 18 sensation units greater than in the unaltered part. As mentioned. above, the unaltered cakin had a reduction factor of 20 units as compared with outside measurements. It thus appears that the treatment applied to the cabin gave a reduction factor of 38 .

Observations were made as to the ease with which conversation could be carried on while the plane was in flight. In the unaltered part of the cabin it was necessary to raise the voice and frequently to repeat a sentence. In the treated portion one could talk in an ordinary tone and be understood by another as far away as tho size of the cabin allowed, and it was seldom necessary to repeat.

It was the judgment of the observers that most of the residual noise in the cabin came through the fioor, which had received no treatment. It is probable that the floor also could be protected against sound if this were done at the time the plane was built. 
TABLE 2

\begin{tabular}{|c|c|c|c|c|c|c|}
\hline \multirow{2}{*}{ Panel Nío. } & \multicolumn{4}{|c|}{$\begin{array}{l}\text { Reduction factor in sensation units at } \\
\quad \text { frequency bands of - }\end{array}$} & \multirow{2}{*}{$\begin{array}{l}\text { Weight } \\
\text { per } \\
\text { square } \\
\text { foot }\end{array}$} & \multirow{2}{*}{$\begin{array}{l}\text { Log of } \\
\text { weight } \\
\text { per } \\
\text { square } \\
\text { foot }\end{array}$} \\
\hline & $150-220$ & $400-470$ & $1,000-1,120$ & A verage & & \\
\hline $\begin{array}{ll}1 \\
4 \\
4 \\
3 \\
3\end{array}$ & $\begin{array}{r}24.5 \\
16.1 \\
5.5 \\
16.6 \\
9.6\end{array}$ & $\begin{array}{r}25.7 \\
17.3 \\
6.6 \\
16.4 \\
15.8\end{array}$ & \begin{tabular}{r|}
26.5 \\
20.3 \\
8.3 \\
16.1 \\
16.9
\end{tabular} & $\begin{array}{r}25.5 \\
17.9 \\
6.8 \\
16.4 \\
14.1\end{array}$ & $\begin{array}{l}\text { Pounds } \\
1.2 \\
.35 \\
.075 \\
.33 \\
.30\end{array}$ & $\begin{array}{r}0.08 \\
-.46 \\
-1.12 \\
-.48 \\
-.52\end{array}$ \\
\hline 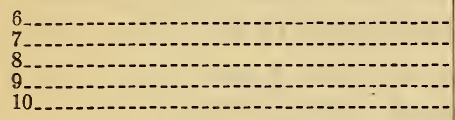 & $\begin{array}{l}17.1 \\
21.4 \\
20.9 \\
17.5 \\
18.6\end{array}$ & $\begin{array}{l}20.3 \\
23.3 \\
16.3 \\
18.7 \\
20.8\end{array}$ & $\begin{array}{l}24.0 \\
25.0 \\
20.3 \\
21.8 \\
24.5\end{array}$ & $\begin{array}{l}20.5 \\
23.2 \\
19.2 \\
19.3 \\
21.3\end{array}$ & $\begin{array}{l}.63 \\
.75 \\
.36 \\
.52 \\
.73\end{array}$ & $\begin{array}{l}=.20 \\
=.12 \\
=.44 \\
=.28 \\
=.14\end{array}$ \\
\hline${ }_{11}^{11} 13$ & $\begin{array}{r}1.6 \\
5.3 \\
24.7 \\
28.7 \\
7.4\end{array}$ & $\begin{array}{r}1.8 \\
6.7 \\
27.0 \\
32.0 \\
9.5\end{array}$ & $\begin{array}{r}2.3 \\
11.2 \\
32.0 \\
34.2 \\
9.5\end{array}$ & $\begin{array}{r}1.9 \\
7.7 \\
27.9 \\
31.6 \\
8.8\end{array}$ & $\begin{array}{l}.017 \\
.10 \\
1.6 \\
3.65 \\
.20\end{array}$ & $\begin{array}{r}-1.80 \\
-1.00 \\
.20 \\
.56 \\
-.70\end{array}$ \\
\hline $\begin{array}{l}16 \\
17 \\
18 \\
19 \\
20\end{array}$ & $\begin{array}{r}9.8 \\
14.8 \\
14.5 \\
13.2 \\
29.1\end{array}$ & $\begin{array}{l}11.2 \\
11.7 \\
15.1 \\
15.5 \\
27.5\end{array}$ & $\begin{array}{l}16.4 \\
22.0 \\
18.6 \\
15.0 \\
42.8\end{array}$ & $\begin{array}{l}12.5 \\
17.8 \\
16.1 \\
14.6 \\
33.1\end{array}$ & $\begin{array}{r}.33 \\
.43 \\
.70 \\
.70 \\
3.2\end{array}$ & $\begin{array}{l}-.48 \\
=.37 \\
=.16 \\
-.16 \\
.505\end{array}$ \\
\hline $\begin{array}{l}21 \\
22-\cdots- \\
23-\cdots \\
24 \\
25-\cdots \\
25-\cdots\end{array}$ & $\begin{array}{l}\text { 19. } 9 \\
26.2 \\
24.0 \\
19.7 \\
19.6\end{array}$ & $\begin{array}{l}18.8 \\
29.0 \\
25.8 \\
21.3 \\
21.6\end{array}$ & $\begin{array}{l}26.5 \\
37.6 \\
29.7 \\
21.6 \\
20.1\end{array}$ & $\begin{array}{l}21.7 \\
30.9 \\
26.5 \\
20.9 \\
20.4\end{array}$ & $\begin{array}{l}1.04 \\
1.50 \\
1.50 \\
1.33 \\
1.45\end{array}$ & $\begin{array}{l}.02 \\
.18 \\
.18 \\
.12 \\
.16\end{array}$ \\
\hline $\begin{array}{l}26-1 \\
27-1-10\end{array}$ & $\begin{array}{l}18.8 \\
19.3 \\
20.8 \\
26.8 \\
17.6\end{array}$ & $\begin{array}{l}16.2 \\
17.4 \\
27.6 \\
23.1 \\
15.1\end{array}$ & $\begin{array}{l}27.0 \\
29.2 \\
41.8 \\
39.8 \\
31.8\end{array}$ & $\begin{array}{l}20.7 \\
22.0 \\
30.1 \\
29.9 \\
21.5\end{array}$ & $\begin{array}{l}1.33 \\
1.45 \\
1.23 \\
2.06 \\
.90\end{array}$ & $\begin{array}{r}.12 \\
.16 \\
.09 \\
.31 \\
-.05\end{array}$ \\
\hline $\begin{array}{l}31 \\
32 \\
33 \\
34 \\
35\end{array}$ & $\begin{array}{l}22.5 \\
22.3 \\
26.7 \\
22.0 \\
20.3\end{array}$ & $\begin{array}{l}23.2 \\
24.0 \\
25.9 \\
27.5 \\
30.9\end{array}$ & $\begin{array}{l}33.7 \\
32.7 \\
37.6 \\
34.9 \\
43.9\end{array}$ & $\begin{array}{l}26.5 \\
27.0 \\
30.1 \\
29.8 \\
31.7\end{array}$ & $\begin{array}{r}.89 \\
1.08 \\
.97 \\
1.06 \\
1.31\end{array}$ & $\begin{array}{r}-.05 \\
.03 \\
-.01 \\
.03 \\
.12\end{array}$ \\
\hline 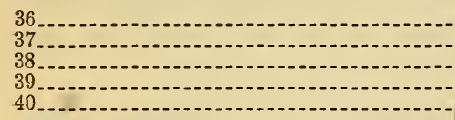 & $\begin{array}{l}31.4 \\
29.1 \\
20.7 \\
26.0 \\
23.6\end{array}$ & $\begin{array}{l}32.2 \\
26.9 \\
26.9 \\
24.5 \\
35.6\end{array}$ & $\begin{array}{l}40.6 \\
39.4 \\
43.7 \\
29.4 \\
45.0\end{array}$ & $\begin{array}{l}34.7 \\
31.8 \\
30.4 \\
26.6 \\
36.4\end{array}$ & $\begin{array}{l}1.57 \\
1.23 \\
1.31 \\
1.20 \\
.97\end{array}$ & $\begin{array}{r}.20 \\
.09 \\
.12 \\
-.08 \\
-.01\end{array}$ \\
\hline
\end{tabular}

\section{DESCRIPTION OF PANELS}

Unless otherwise specified the materials were fastened to a wood frame made out of $13 / 4$ by $13 / 4$ inch stock. The outside dimensions of the panels were 25 by $43 \frac{1}{2}$ inches.

Panel

No.

1. Single sheet of galvanized iron 0.03 inch thick.

2. Single sheet of aluminum 0.025 inch thick.

3. Single sheet of aluminum 0.006 inch thick.

4. Single sheet of duralumin 0.020 inch thick.

5. Single sheet of aluminum-coated duralumin.

6. Single sheet of standard Celotex building board $7 / 16$ inch thick.

7. Single shect of Insulite $1 / 2$ inch thick.

8. Single sheet of Insulite $1 / 4$ inch thick.

9. Single sheet of plywood $1 / 8$ inch thick.

10. Single sheet of plywood $1 / 4$ inch thick. 
11. Single sheet of wrapping paper 0.006 inch thick.

12. Single sheet of airplane fabric, doped five times, varnished two times.

13. Single sheet of double-strength glass $1 / 3$ inch thick.

14. Single sheet of plate glass $1 / 4$ inch thick.

15. Single sheet of $1 / 2$ inch balsam wool, paper on both sides.

16. Single sheet of 1 inch balsam wool, paper on both sides.

17. Single sheet of Insulite $5 / 16$ inch thick.

18. Two sheets 0.025 -inch aluminum separated by $1 / 2$-inch air space.

19. Two sheets 0.025 -inch aluminum separated by $1 \frac{134}{4}$-inch air space.

20. Two sheets double-strength glass separated by $1 / 2$-inch air space.

21. Two sheets $1 / 8$-inch plywood separated by $13 / 4$-inch air space.

22. Two sheets $1 / 2$-inch Insulite separated by $1 \frac{1}{4} 4$-inch air space.

23. Two sheets $1 / 2$-inch Insulite placed together.

24. Single sheet 0.025 -inch aluminum, one sheet $7 / 16$-inch Celotex, second sheet aluminum.

25. Single sheet 0.025 -inch aluminum, one sheet $1 / 2$-inch Insulite, second sheet aluminum.

26. Single sheet 0.025 -inch aluminum, $5 / 8$-inch air space, one sheet $7 / 16$-inch Celoter, $5 / 8$-inch air space, second sheet aluminum.

27. Single sheet 0.025 -inch aluminum, $5 / 8$-inch air space, one sheet $1 / 2$-inch Insulite, $5 / 8$-inch air space, second sheet aluminum.

28. Single sheet aluminum, $1 / 2$-inch layer balsam wool covered on both sides with paper, 1-inch layer balsam wool covered on both sides with paper, second sheet aluminum.

29. Single sheet 0.025 -inch aluminum, 2 layers 1 -inch hair felt, second sheet aluminum.

30. Single sheet 0.025 -inch aluminum, $1 / 2$-inch layer balsam wool covered on both sides with paper, second sheet aluminum.

31. Single sheet 0.025 -inch aluminum, one layer 2-inch Dry Zero blanket, second sheet aluminum.

32. Single sheet 0.025 -inch aluminum, 2 layers 2 -inch Dry Zero blanket, second sheet aluminum.

33. Single sheet 0.025 -inch aluminum, one layer 2-inch Dry Zero blanket, on sheet $5 / 16$-inch Insulite.

34. Single sheet 0.025 -inch aluminum, one layer 2-inch Dry Zero blanket, one sheet $1 / 8$-inch plywood.

35. Single sheet 0.025 -inch aluminum, $1 / 2$-inch layer balsam wool covered on both sides with paper, 1-inch layer balsam wool covered on both sides with paper, $5 / 16$-inch sheet Insulite.

36. Single sheet $1 / 3$-inch plywood, $1 / 2$-inch layer balsam wool covered on both sides with paper, 1-inch layer balsam wool covered on both sides with paper, $1 / 8$-inch sheet plywood.

37. Single sheet $1 / 8$-inch plywood, one layer 2 -inch Dry Zero blanket, second sheet $1 / 8$-inch plywood.

38. Single sheet 0.025 -inch aluminum, $1 / 2$-inch layer balsam wool with paper on both sides, single sheet 0.006 -inch aluminum, 1 -inch layer balsam wool with paper on both sides, sheet of 0.025 -inch aluminum.

39. Single sheet 0.025 -inch aluminum, four layers cotton approximately $1 / 2$ inch thick separated by sheets of wrapping paper, second sheet of aluminum.

40. This was a large panel 70 by 84 inches made of $13 / 4$ by $1 \frac{3 / 4}{4}$ inch stock. There were crosspieces running the shorter way approximately 16 inches apart. Sheets of aluminum 0.025 inch thick were fastened on one side of this frame. Two-inch Dry Zero blanket was cut up and placed in the spaces between the framework. The opposite side was covered with sheets of 5/10-inch Insulite. 


\section{CONCLUSIONS}

Though airplane noises are intense and there is a limit to the additional weight that a plane may carry, it has been found that by a comparatively moderate increase in weight the sound intensity in an airplane cabin can be reduced to a degree where conversation can easily be maintained.

It should also be noted that the structure used was found to be an excellent heat insulator, and should make the cabin comfortable from the standpoint of temperature in even the coldest weather or at high altitudes.

Sound insulation installed during the construction of the plane, with care as to details, should give even better results than those obtained in the experiments described.

Washington, January 22, 1929. 